\title{
APTNESS AND SAFETY: HOW ARE THEY RELATED?
}

\author{
Miguel Ángel FernándeZ \\ Instituto de Investigaciones Filosóficas \\ Universidad Nacional Autónoma de México \\ mafv@filosoficas.unam.mx
}

Summary: In A Virtue Epistemology, Ernest Sosa defines the notions of safety and aptness of beliefs and uses them to characterize two kinds of knowledge, animal and reflective. This paper tries to bring out what I take as an incoherence in Sosa's views concerning how safety and aptness relate to knowledge and to each other. I discuss an apparent counterexample Sosa gives to his final view that aptness suffices for animal knowledge and argue that in fact the principle on which Sosa responds to the counterexample does not permit the response he offers. The principle in question is problematic for Sosa's epistemology in a deeper way: it doesn't seem to cohere with Sosa's view that only aptness, not safety, is required for animal knowledge.

KEY WORDS: animal knowledge, Ernest Sosa, reflective knowledge, skepticism, virtue epistemology

RESUMen: En A Virtue Epistemology, Ernesto Sosa define las nociones de seguridad y aptitud de las creencias y las usa para caracterizar dos clases de conocimiento, el animal y el reflexivo. En este artículo discuto lo que parece una incoherencia en las tesis de Sosa acerca de cómo se relacionan la seguridad y la aptitud con el conocimiento y entre sí. Examino un aparente contraejemplo que Sosa plantea a su tesis final de que la aptitud es suficiente para el conocimiento animal, y argumento que el principio que él usa para responder al contraejemplo de hecho no permite dar esa respuesta. El principio en cuestión es problemático para la epistemología de Sosa de una manera más profunda: no parece ser coherente con su tesis central de que sólo la aptitud, no la seguridad, es necesaria para el conocimiento animal.

PALABRAS CLAVE: conocimiento animal, conocimiento reflexivo, epistemología de las virtudes, Ernesto Sosa, escepticismo

A Virtue Epistemology. Apt Belief and Reflective Knowledge, Volume $I$, distills into a slim, short book Ernest Sosa's numerous and scattered reflections on the foundations of virtue epistemology, spanning for more than twenty years. When Sosa first wrote about the idea of making the notion of epistemic virtue the crux of a model of epistemic evaluation, the idea was found novel and promissory. Today, virtue epistemology is a flourishing and branching program of research; this would be inconceivable without Sosa's contributions. Here I have the honor to comment on the mature views of the initiator of this contemporary tradition, as they appear condensed in his latest book. 


\section{Aptness and Safety Introduced}

Sosa's virtue epistemology supplies a conceptual repertoire that enables one to evaluate an agent from an epistemic point of view. Standard accounts of virtue epistemology set forth as one of its central innovations, relative to rival models of epistemic evaluation, that it shifts the focus of evaluation from the agent's beliefs to his intellectual traits. However, this should not be understood as implying that the evaluation of belief disappears from the concerns of virtue epistemology, on the contrary, many virtue epistemologists are still explicitly in the business of defining normative properties of beliefs. Sosa's own theory is an example of this: the notion of epistemic competence is used throughout the book as a component in several definientia, but the definienda are still normative properties of beliefs, especially those that distinguish mere true belief from various kinds of knowledge.

At the heart of Sosa's virtue epistemology there are two normative properties of belief that Sosa calls "aptness" and "safety", which he defines as follows:

[SAFETY] What is required for the safety of a belief is that not easily would it fail by being false, or untrue. A belief that $p$ is safe provided it would have been held only if (most likely) $p$. (Sosa 2007, p. 25, his emphasis) $^{1}$

[APTNESS] The requirement [for aptly believing] is that one believe correctly (with truth) through the exercise of a competence in its proper conditions. (p. 33, his emphasis)

Sosa's notion of aptness has gone through some evolution. In its original form, in his seminal papers of the late eighties, it meant something very close to belief formed through the exercise of a reliable virtue (Sosa's way of doing justice to reliabilist intuitions in the theory of justification). ${ }^{2}$ In its present form, the notion emphasizes that the success of believing with truth must be attributable to the believer's competences, an emphasis not present in the earlier formulations. In what follows we will work only with his most recent notion of aptness.

\footnotetext{
${ }^{1}$ Hereafter, page numbers in parentheses, without further indication of author or year, refer to Sosa 2007. See bibliography for full details.

${ }^{2}$ See Sosa 1991, pp. 143-144, 288-290, for discussion of his earlier notion of aptness.
} 
Sosa's notion of safety is his version of the widely shared view that knowledge involves a modally strong condition that guarantees the non-accidentality of believing with truth. Sosa's safety contrasts, in particular, with another such modal condition that has come to be known as sensitivity: "[S]omeone's belief that $p$ is sensitive if and only if were it not so that $p$, he would not (likely) believe that $p "$ (p. 25). Sosa says that safety is the contrapositive of sensitivity, but reminds us that contraposing subjunctive conditionals does not preserve truth and therefore a belief can be safe even if it is not sensitive, a result that Sosa uses in his response to radical skeptical scenarios and sees as an advantage of his notion of safety over sensitivity in an account of knowledge. ${ }^{3}$

\section{Aptness, Safety and Two Levels of Knowledge}

Sosa uses the notions of safety and aptness to draw a distinction of central importance in his epistemology between two kinds of knowledge: animal knowledge and reflective knowledge. Initially, Sosa thinks that both, safety and aptness, are necessary for animal knowledge. Regarding aptness he writes: "Animal knowledge is essentially apt belief [...]" (p. 24). Concerning safety, however, he notes that some clear cases of knowledge are not cases of "outright safe belief" (p. 26) and then replaces outright safety for "basis-relative safety" as a necessary condition for animal knowledge:

[BASIS-RELATIVE SAFETY] What is required of one's belief if it is to constitute knowledge, is at most its having some basis that it would not easily have had unless true, some basis that it would (likely) have had only if true. (p. 26)

The difference between safety outright and basis-relative safety is that the latter relativizes the safety of the belief to some further conditions. For example, my true belief that I have an awful headache right now is not outright safe, because I could easily have believed falsely that I have an awful headache; for example, if I had experienced only discomfort and believed that I had an awful headache out of hypochondria. In contrast, the belief is safe relative to the basis on which I actually believe, for I could not have believed falsely that

${ }^{3}$ It is debatable whether Sosa's notion of safety really is the contrapositive of sensitivity. See DeRose 2004, esp. pp. 31-33, for discussion of this point. What matters for Sosa's purposes, however, is that safety doesn't entail sensitivity, which is clearly so. 
I have an awful headache, if I believed on the basis of my having an awful headache.

Reflective knowledge is different from, but importantly related to, animal knowledge: "the key component of the distinction [between animal and reflective knowledge] is the difference between apt belief simpliciter, and apt belief aptly noted. If $\mathrm{K}$ represents animal knowledge and $\mathrm{K}+$ reflective knowledge, then the basic idea may be represented thus: $\mathrm{K}+p \Leftrightarrow \mathrm{KK} p$ " (p. 32).

According to this, reflective knowledge that $p$ is simply an apt belief that one has an apt belief that $p$. So, aptness is necessary for reflective knowledge. Although Sosa does not explicitly address the issue whether reflective knowledge also requires basis-relative safety, he is committed to hold such a view. For given that he conceives reflective knowledge as a simple iteration of animal knowledge, and given that animal knowledge requires basis-relative safety, it follows that second-order animal knowledge requires it too. Therefore, both aptness and basis-relative safety are necessary for reflective knowledge, as much as they are for animal knowledge. ${ }^{4}$

However, Sosa's views on how safety and aptness relate to animal and reflective knowledge change through his book. Sosa develops his views on the matter guided by a central desideratum: respect and explain common sense, i.e. the view that we have plenty of animal and reflective knowledge in the areas we ordinarily think we know many things, for example, in standard cases of perception. If at any point his views seem to have the consequence that we lack common sense knowledge, then something must be adjusted in those views in order to avoid such a conclusion. In what follows I want to discuss the adjustments he makes to his views on how safety and aptness relate to animal and reflective knowledge, and to each other, in order to keep their consequences in line with common sense. I shall try to bring out the difficulties I met in trying to extract, from Sosa's

${ }^{4}$ As I said above, Sosa's notion of aptness has gone richer, compared with its earlier formulations; since animal knowledge is defined in terms of aptness, his notion of animal knowledge has gone correspondingly richer too. In contrast, his notion of reflective knowledge appears to have gone thinner, compared with its earlier formulations, where it included the idea of one's belief fitting coherently within one's epistemic perspective and one achieving an understanding of the place of one's belief within such a perspective. None of these ideas appears in his official definition of reflective knowledge as merely a simple iteration of animal knowledge; however, ideas of comprehensiveness and coherence reappear in Sosa's thinking about the nature of reflective knowledge in the last chapter, "The Problem of the Criterion", of his 2007. See Sosa 1991, pp. 145, 239-241, for a glance at his earlier views on reflective knowledge. 
successive adjustments, a coherent overall picture of how safety and aptness relate to animal and reflective knowledge, and to each other.

\section{First Adjustment: Dream Skepticism}

The initial view that A-knowledge ${ }^{5}$ requires safety has, in Sosa's view, the attraction of allowing a response to those forms of skepticism that exploit remote possibilities of massive error - for example, the brainin-a-vat or the evil-demon scenarios-, a response that is not available if one regards some modal condition other than safety as necessary for knowledge. For instance, although it is true that the belief that we are not in one of those remote scenarios is not sensitive, because even if we were in one of them we would still believe that we are not, such beliefs are nevertheless safe because, given how remote those possibilities are, we would not easily believe, on the same experiential basis on which we actually believe, that we are not in one of them when in fact we are. So, if sensitivity were necessary for A-knowledge the skeptic could argue, via closure and applying modus tollens, that we lack A-knowledge of ordinary empirical propositions because we lack A-knowledge that we are not in a radical skeptical scenario. But the skeptic cannot make such a move if safety, instead of sensitivity, is necessary for A-knowledge, for one's belief that one is not in a radical skeptical scenario does satisfy the safety requirement.

However, the view that A-knowledge requires safety and not sensitivity is powerless against other skeptical threat, one that exploits what Sosa regards as closer skeptical possibilities, for example, the dreaming possibility. The dreaming possibility threatens the safety of ordinary perceptual beliefs by making fragile either the competence the believer exercised in forming the belief or the appropriateness of the conditions for its exercise. This means that, given such a possibility, it could easily have happened (hence the closeness of the possibility) that his competence was impaired, or that the appropriateness of the conditions was spoiled, by his being dreaming. In either case, the result is that the agent could easily have believed, on the same basis on which he actually believes it, that he was not dreaming while in fact he was; therefore, his belief that he is not dreaming is not safe, and hence not A-knowledge. If safety is necessary for A-knowledge, the skeptic wins. ${ }^{6}$

\footnotetext{
${ }^{5}$ Hereafter I will use "A-knowledge" as an abbreviation of "animal knowledge".

${ }^{6}$ In this paragraph, and in the rest of the paper, when I speak of "safety" I mean "basis-relative safety", unless otherwise indicated.
} 
To save common sense from such skeptical conclusion Sosa's immediate reaction is to take back the claim that safety is necessary for A-knowledge, but leaving in its place the claim that aptness is:

However unsafe a performer's competence may be, and however unsafe may be the conditions appropriate for its exercise, if a performance does succeed through the exercise of that competence in its appropriate conditions, then it is an apt performance, one creditable to the performer. Knowledge is just a special case of such creditable, apt performance. Perceptual knowledge is unaffected by any fragility either in the knower's competence or in the conditions appropriate for its exercise. The knower's belief can thus remain apt even if unsafe through the proximity of the dream possibility. (p. 31)

The fragility introduced by the closeness of the dream possibility does not threaten the aptness of ordinary perceptual beliefs because, at this stage in Sosa's discussion, aptness does not require the modal strength in achieving success that defines safety. In order for a performance to be apt, it need only succeed as a result of one of the subject's competences exercised in what actually are the normal conditions for the exercise of such competence. What could have happened to the exercise of the competence in relatively close scenarios is not relevant for assessing his aptness. ${ }^{7}$

Sosa concludes that safety is unnecessary for A-knowledge, while aptness remains as necessary, or as he puts it: "only aptness is required for animal knowledge, not safety" (p. 34). But, in fact, from this response to dream skepticism, Sosa proceeds as if aptness is not just necessary but also sufficient for A-knowledge. He claims, for instance, that according to his solution to dream skepticism: "despite the proximity of the dream possibility, perceptual beliefs are nonetheless apt and therefore knowledge" (p. 31, my emphasis). This is a way of saying that aptness suffices for knowledge.

One puzzling feature of the present adjustment that Sosa makes on his views is this: his response to the form of skepticism that exploits remote possibilities of error relied on the claim that, although one's beliefs that one is not in one of such scenarios are not sensitive, they are safe. But now, if Sosa wants to hold that safety is unnecessary for A-knowledge, this seems to undercut his very response to radical skepticism: the claim that those beliefs are safe would be irrelevant for the question whether they are knowledge. What would

${ }^{7}$ The modal status of aptness is much more problematic; I discuss it in sections 6 and 7 below. 
then be Sosa's response to radical skepticism? Arguably, it would also be based on the claim that aptness is necessary and sufficient for A-knowledge. That would homogenize his responses to both forms of skepticism. ${ }^{8}$ But how would it exactly go? This brings us to the point that Sosa doesn't seem to expect the same from his various responses to skepticism; for his first response seems to warrant only the claim that the skeptic has not shown that we don't know, whereas the second response seems to aspire to show that we do know. In effect, in his response to radical skepticism in terms of the claim that safety is necessary for A-knowledge, it seems to be the former aspiration that is manifested; while in his response to dream skepticism in terms of the claim that aptness is necessary and sufficient for A-knowledge, it seems to be the latter idea that is present. The claim that it is safety and not sensitivity what is necessary for A-knowledge, conjoined with the claim that the skeptic has only shown that our belief that we are not in a remote skeptical scenario is not sensitive, doesn't entail that we do have A-knowledge, but only that the skeptic hasn't shown that a necessary condition for A-knowledge is unfulfilled. Adding the lemma that such belief about one not being in a remote skeptical scenario is in fact safe, still falls short from showing that we do have A-knowledge, for safety has been said to be necessary, but not that it is sufficient, for A-knowledge.

In contrast, Sosa's response to dream skepticism seems to have a different strength, for here the claim is not only that aptness is necessary and sufficient for A-knowledge and that the skeptic has not shown that our beliefs are not apt, but also - the positive claimthat our beliefs are apt, which entails that we do have A-knowledge. Sosa clearly regards this latter claim as A-known, for A-knowing that a belief that $p$ is apt is equivalent to having reflective knowledge that $p$, and he holds that his virtue epistemology can show that we do posses reflective knowledge (p. 43). Therefore, Sosa's epistemology goes for the stronger response to the forms of skepticism considered: not just a demonstration that the skeptic has failed to establish our lack of A-knowledge, but a demonstration that we do posses A-knowledge. ${ }^{9}$

${ }^{8}$ As he himself notes: "This aptness-centered account enables a solution not only to the problem of radical skepticism, but also to the more difficult problem of dream skepticism" (p. 136).

${ }^{9}$ In this paper, when I talk about Sosa's responses to skepticism I'm referring to his virtue-theoretic responses to skepticism, that is to say, the responses that rely on theses specific to his virtue epistemology. I do not consider at all Sosa's response to dream skepticism developed in chapter I: "Dreams and Philosophy", of 
Sosa's strong response to skepticism is based on the claim that aptness is necessary and sufficient for A-knowledge; the dialectical path to this claim excluded first sensitivity and then safety from the conditions necessary for A-knowledge. These exclusions seem to contravene the almost axiomatic intuition that propositional knowledge involves some modal condition that guarantees not just actual success, but success in nearby possibilities. To the extent that Sosa understands aptness as "unaffected" (p. 31) by nearby possibilities of error, such aptness condition seems to be insufficient for propositional knowledge of whatever sort. The central problem with Sosa's views on safety and aptness that I want to highlight arises in this connection from the manoeuvre he feels obliged to make in order to deal with an apparent counterexample to his view that aptness is necessary and sufficient for knowledge. Close inspection of the manoeuvre suggests that a modal condition, arguably equivalent to safety, pushes itself back into his final account of the conditions for A-knowledge.

\section{Second Adjustment: The Kaleidoscope and the Jokester}

Sosa presents an apparent counterexample to his claim that aptness suffices for animal knowledge: One sees a surface that looks red, it is red and one believes that it is red, but it is a kaleidoscope surface controlled by a jokester, who also controls the lighting. He in fact is presenting to one a combination white-light + red surface, but he might as easily have presented to one a red-light + white surface combination. Sosa asks if one's belief that the surface is red is a case of A-knowledge, and answers as follows:

Arguably, your belief that the surface is red is an apt belief, in which case it amounts to knowledge, or so it does according to our account. For you then exercise your faculty of color vision in normal conditions of lighting, distance, size of surface, etc., in conditions generally appropriate for the exercise of color vision. Yet it is not easy to insist that you therefore know that surface to be red. (p. 31)

Sosa sees in this a threat to his solution to dream skepticism, for if aptness is not sufficient for A-knowledge, then even if ordinary

his 2007, which is not virtue-theoretic. In that chapter, Sosa challenges the skeptic's assumption that while dreaming one can actually assent and believe; in contrast, Sosa's virtue-theoretic responses grant that assumption and still go ahead to (try to) refute the skeptic. 
perceptual beliefs are apt that would not be enough to ensure, against the skeptic, that they are A-knowledge. Sosa protects the claim that aptness suffices for A-knowledge by relocating the damage caused by the seeming counterexample. He argues that the example does not really present a case where a subject has an apt belief that $p$ but lacks animal knowledge that $p$, but rather one in which the subject has an apt belief that $p$ but lacks reflective knowledge that $p$. $\mathrm{He}$ reasons as follows:

[T]he requirement for aptly believing is not just that one's beliefs be true, and derive from a competence. The requirement is rather that one believe correctly (with truth) through the exercise of a competence in its proper conditions. What must be attributable to the competence is not just the belief's existence but its correctness. (p. 33)

In his view, a necessary condition for aptly believing that $p$ is that the correctness of the belief that $p$ is attributable to a competence of the believer. He then goes on to specify a conjunctive necessary condition for the attributability of the correctness of a belief to a competence:

C. For any correct belief that $p$, the correctness of that belief is attributable to a competence only if it derives from the exercise of that competence in appropriate conditions for its exercise, and that exercise in those conditions would not then too easily have issued a false belief. (p. 33)

If such a conjunctive condition is necessary for the attributability of the correctness of the belief that $p$ to a subject's competence, and such attributability is in turn necessary for the aptness of the belief that $p$, then, by the transitivity of necessary conditions, such a conjunctive condition is necessary for the aptness of the belief that $p$.

Sosa uses C to explain why the subject in the kaleidoscope example lacks reflective knowledge as follows: the subject's belief that he aptly believes the surface to be red is the result of what Sosa calls a "default competence" that takes it for granted that the conditions necessary for aptly believing that the surface is red - for example the condition that the lighting is normal- obtain. But given that the jokester is in control of the lighting, such a default competence "might then too easily have issued a false belief that the lights are normal" (p. 33), and then, given condition C, the correctness of the subject's belief that he aptly believes the surface to be red cannot be attributable to 
his competence, and hence such a meta-belief is not apt. The subject then lacks an apt belief that he aptly believes the surface to be red, which means that he lacks reflective knowledge that the surface is red. But in Sosa's view the subject does have an apt belief that the surface is red, for such belief is the result of exercising the subject's competent color vision in normal conditions of lighting, distance, etc., which are conditions appropriate for the exercise of color vision generally, and that exercise in those conditions would not too easily have issued a false belief about the color of the surface. The subject then has an apt belief simpliciter that the surface is red, which means that he has animal knowledge that the surface is red.

The apparent challenge to the view that aptness suffices for animal knowledge has been dispelled, for the intuition in the kaleidoscope example that the subject lacks some knowledge of the surface, despite the aptness of his belief that the surface is red, is indeed correct, but the knowledge he lacks is reflective, not animal knowledge. Ernest Sosa's thesis that aptness is sufficient for A-knowledge has not been disproved.

\section{The Kaleidoscope Perceiver and the Ordinary Perceiver: A Disparity}

The above treatment of the kaleidoscope example, however, creates a new threat for common sense, for if ordinary perceptual beliefs are in relevant respects like the perceptual belief of the subject in the kaleidoscope case, then no ordinary perceptual A-knowledge that $p$ could ascend to the status of R-knowledge that $p .^{10}$ In particular, if the effect of the possibility that one might have been dreaming upon one's ordinary perceptual beliefs is analogous to the effect of the possibility that the jokester might have presented to one the red light + white surface combination upon one's belief that the surface is red, then, by parity of reasons, in the ordinary case one could not have an apt belief that one aptly believes that $p$, i.e. one couldn't have R-knowledge that $p$. If common sense is to prevail, Sosa says, we must show that ordinary perceptual A-knowledge can ascend to the status of R-knowledge (p. 35). And that is exactly what he does; he argues that the effect of the threat posed by the possibility of dreaming upon ordinary perceptual belief is not analogous to the effect of the threat posed by the jokester to one's belief about the color of the surface. One of the controversial issues I will discuss in

${ }^{10}$ Hereafter I use "R-knowledge" as an abbreviation of "reflective knowledge". 
the next section is what exactly the disanalogy is supposed to be. At this point I need only describe Sosa's argument for the disanalogy.

As I've said, according to Sosa, both the kaleidoscope perceiver and the ordinary perceiver have A-knowledge that $p$, because the object-level beliefs of both fulfill the two parts of the conjunctive condition $\mathrm{C}$ quoted above. It will be helpful to have the two parts of condition C clearly separated:

For any correct belief that $p$, the correctness of that belief is attributable to a competence only if

$\mathrm{C}_{i}$ : it derives from the exercise of that competence in appropriate conditions for its exercise, and

$\mathrm{C}_{i i}$ : that exercise in those conditions would not then too easily have issued a false belief.

According to Sosa, both perceivers obtain their corresponding true beliefs that the surface is red ${ }^{11}$ through the exercise of a normal perceptual competence, that consists of a disposition "to accept a range of material conditionals of the following form: if it appears $\mathrm{F}$, then it is $F^{\prime \prime}$ (p. 107). In both cases such competence is exercised in its normal conditions (p. 110), and in those conditions the exercise of the competence would not easily have produced a false belief. This is to say that both perceivers have A-knowledge that $p$ because both fulfill conditions $\mathrm{C}_{i}$ and $\mathrm{C}_{i i}$ for having the correctness of their beliefs attributed to one of their competences, and hence for being apt beliefs. ${ }^{12}$

In contrast, Sosa argues that the ordinary perceiver does have an apt belief that he has an apt belief that $p$-i.e. R-knowledge that $p$-, whereas the kaleidoscope perceiver doesn't have it. Following the same pattern of explanation as before, this would have to be because the second-level belief of the ordinary perceiver does fulfill conditions $\mathrm{C}_{i}$ and $\mathrm{C}_{i i}$, whereas the second-level belief of the kaleidoscope perceiver doesn't fulfill at least one of these conditions.

It is clear that Sosa thinks that both perceivers obtain their corresponding true second-level beliefs through the exercise of the same

${ }^{11}$ Here, I am implicitly imagining a case where the ordinary perceiver believes that a surface in front of him is red but, of course, in his case there's no kaleidoscope and no jokester; everything is normal.

${ }^{12}$ Note that, strictly speaking, the complex condition $\mathrm{C}$ is originally stated as merely necessary for a belief to be apt (p. 33); however, in most of his discussion Sosa treats it as if fulfillment of it was sufficient for apt belief. This is manifest in the present and the following paragraphs of my exposition of Sosa's views. 
"meta-competence", which consists of "a default competence of taking it for granted that conditions are appropriately normal" (p. 111). Concerning the question whether both exercise that competence in appropriately normal conditions, Sosa is less sure. He cautiously offers a disjunction as an answer to this question. He says that either the kaleidoscope perceiver, like the ordinary perceiver, exercises the meta-competence in normal conditions for its exercise or the very presence of the jokester spoils the normality of those conditions (pp. 36, 111). If the second disjunct of this claim is the truth, then the kaleidoscope perceiver fails to satisfy condition $\mathrm{C}_{i}$ and, therefore, his true second-level belief that he has an apt belief that the surface is red is not itself apt, and then lacks R-knowledge that the surface is red. On the other hand, if the first disjunct is the truth, then the kaleidoscope perceiver is still on a par with the ordinary perceiver, and both exercise their meta-competence in normal conditions. But, in those circumstances, Sosa says that although the conditions where the kaleidoscope perceiver exercises his meta-competence are in fact normal, the presence of the jokester makes it the case that the exercise of that competence in those conditions might easily have produced the false belief that the lighting conditions are good. This means that the kaleidoscope perceiver fails to fulfill condition $\mathrm{C}_{i i}$ and hence his true second-level belief is not itself apt, and then lacks R-knowledge that the surface is red. So, whether or not the presence of the jokester spoils the normality of the conditions for the exercise of the perceiver's meta-competence, he fails to fulfill either condition $\mathrm{C}_{i}$ or condition $\mathrm{C}_{i i}$ with respect to his second-level belief that he has an apt belief that the surface is red, and then lacks R-knowledge that the surface is red.

If Sosa is to hold that, unlike the kaleidoscope perceiver, the ordinary perceiver can attain R-knowledge that the surface is red, that must be on the grounds that the second-level belief of the ordinary perceiver does fulfill conditions $\mathrm{C}_{i}$ and $\mathrm{C}_{i i}$. He does say that the ordinary perceiver's belief fulfills condition $\mathrm{C}_{i}$ : he exercises his meta-competence in appropriately normal conditions, which is incontrovertible. But Sosa does not address the controversial point of how that normal perceiver can fulfill condition $\mathrm{C}_{i i}$, despite the alleged proximity of the dreaming possibility (recall that Sosa treats the dreaming possibility as a close one). How could it be true that the exercise of his meta-competence would not then too easily have issued a false belief that the conditions for the exercise of his objectlevel competence are normal, if he might easily have been dreaming, and then believing falsely that such conditions are normal? Instead 
of addressing this worry, he points out that when we are actually dreaming, our meta-competence is impaired by the very fact that we are dreaming (p. 111), and hence we would not be using a normal competence as the complex condition $\mathrm{C}$ demands. But this is off the point, for we are assessing whether the ordinary perceiver can obtain R-knowledge, given the proximity of the dreaming possibility, not whether someone who is in fact dreaming can obtain that kind of knowledge. An individual who is dreaming ipso facto isn't in the situation of the type of perceiver we are assessing.

It is unclear why we should think that the ordinary perceiver's meta-belief does fulfill condition $\mathrm{C}_{i i}$, and so the question remains open whether the epistemic situations of the ordinary perceiver and the kaleidoscope perceiver are disanalogous up to the point that only the former has R-knowledge.

\section{Who Lacks Reflective Knowledge?}

Let us have clear in view the following facts about the kaleidoscope perceiver and the ordinary perceiver, in relation with their secondlevel belief that their belief that the surface is red is apt:

\begin{tabular}{|l|l|l|}
\hline & Ordinary Perceiver & Kaleidoscope Perceiver \\
\hline Competence exercised & $\begin{array}{l}\text { Meta-competence of taking } \\
\text { it for granted that conditions } \\
\text { are appropriately normal }\end{array}$ & The same \\
\hline $\begin{array}{l}\text { Normal conditions for the ex- } \\
\text { ercise of the competence }\end{array}$ & $?$ & $?$ \\
\hline $\begin{array}{l}\text { Dangers to the exercise of } \\
\text { the competence }\end{array}$ & $\begin{array}{l}\text { The possibility that one might } \\
\text { have been dreaming }\end{array}$ & $\begin{array}{l}\text { The possibility that the joke- } \\
\text { ster might have presented } \\
\text { the red light + white surface } \\
\text { combination }\end{array}$ \\
\hline
\end{tabular}

It is clear that in both cases the same meta-competence is exercised, but note that the conditions that the meta-competence takes by default to be normal are the conditions for the exercise of the object-level competence, which are conditions of lighting, distance, etc. But what are the normal conditions for the exercise of the metacompetence itself? Sosa is sure that the danger of the jokester and the danger of dreaming do not affect the normality of the conditions for the exercise of the object-level competence (p. 110), but, as we've seen, he is unsure whether to consider that the danger of the jokester spoils the normal conditions for the exercise of the meta-competence (pp. 36, 111). The differential certainty of Sosa in this regard reveals 
that he implicitly assumes that such a set of conditions is different from the set of normal conditions for the exercise of the object-level competence. The question then is this: what are the normal conditions for the exercise of the meta-competence if they are different from the normal conditions for the exercise of the object-level competence? Whatever those conditions exactly are, a plausible hypothesis is that the normal conditions for the exercise of the meta-competence include as a proper set the normal conditions for the object-level competence. This is suggested by some of Sosa's remarks, for example, he says that when the danger of dreaming is actually realized, and hence the conditions for the object-level competence are abnormal, the conditions for the meta-competence are abnormal too (p. 37). In the discussion that follows I will assume that

A. the normal conditions for the meta-competence include the normal conditions for the object-level competence.

I will also assume that

B. the normality of the conditions for the meta-competence, like the normality of the conditions for the object-level competence, is not affected by the danger of the jokester nor by the danger of dreaming.

Assumption B entails that the second-level beliefs of both the kaleidoscope and the normal perceivers satisfy condition $\mathrm{C}_{i}$, and this enables us to focus on the controversial point concerning what the impact of those dangers upon satisfaction of condition $\mathrm{C}_{i i}$ is.

Recall that the reason why the second-level belief of the kaleidoscope perceiver fails to satisfy condition $\mathrm{C}_{i i}$ is that the danger of the jokester entails that the exercise of the meta-competence might easily have produced the false belief that the conditions for the exercise of the perceptual object-level competence are normal. To the extent that the jokester might have intervened, the exercise of the metacompetence is one that might easily have produced the false belief that the conditions for the exercise of the object-level competence are normal, for when the jokester is actually intervening, such conditions are not normal (in particular, the lighting conditions become abnormal).

But an exactly analogous claim seems to apply to the normal perceiver: the danger of dreaming entails that the exercise of the meta-competence might easily have produced the false belief that 
the conditions for the exercise of the object-level competence are normal. To the extent that one might have been dreaming, the exercise of the meta-competence is one that might easily have produced the false belief that the conditions for the exercise of the object-level competence are normal, for when one is dreaming such conditions are not normal (in particular, one's perceptual competence is impaired).

It seems that the reason that makes the second-level belief of the kaleidoscope perceiver fail to satisfy condition $\mathrm{C}_{i i}$ also makes the second-level belief of the normal perceiver fail to satisfy it. If the former perceiver lacks reflective knowledge, so does the later, and for the same reason.

But does the second-level belief of the kaleidoscope perceiver fail to satisfy $\mathrm{C}_{i i}$ for the reason adduced by Sosa? Recall the exact phrasing of $\mathrm{C}_{i}$ and $\mathrm{C}_{i i}$ :

For any correct belief that $p$, the correctness of that belief is attributable to a competence only if

$\mathrm{C}_{i}$ : it derives from the exercise of that competence in appropriate conditions for its exercise, and

$\mathrm{C}_{i i}$ : that exercise in those conditions would not then too easily have issued a false belief.

Now, the correct belief in question is the second-level belief that the conditions for the exercise of the object-level competence are normal. Given the assumption B above, the exercise of the metacompetence that leads to this second-level belief takes place in normal conditions; and given assumption A, this means that the normal conditions for the object-level competence also obtain. On these assumptions, it seems that if the second-level belief satisfies $\mathrm{C}_{i}$ then it cannot fail to satisfy $\mathrm{C}_{i i}$. For if the meta-competence is actually exercised in its normal conditions, then in order to determine if it satisfies $\mathrm{C}_{i i}$ we have to keep those conditions fixed and see if in those conditions that meta-competence could easily have produced the false belief that the normal conditions for the object-level competence obtain. This is so because the anaphor "in those condition" in $\mathrm{C}_{i i}$ makes reference to the normal conditions for the exercise of the meta-competence. But then it is false that, keeping the normal conditions for the exercise of the meta-competence fixed, the exercise of the competence in those conditions could easily have produced the false belief that the conditions for the object-level competence are normal. For if the conditions for the meta-competence are normal, so are the conditions 
for the object-level competence, and then the issued second-level belief that the conditions for the object-level competence are normal cannot fail to be true. Of course, considering the danger posed by the jokester, the exercise of the meta-competence could easily have taken place in abnormal conditions (when the jokester decides to intervene), and then would have produced the false belief that conditions for the object-level competence are normal. But this possibility is irrelevant to assess whether the second-level belief of the kaleidoscope perceiver satisfies $\mathrm{C}_{i i}$, because that possibility violates the restriction in $\mathrm{C}_{i i}$ to exercises of the meta-competence in situations where normal conditions do obtain. An exercise of the meta-competence can produce a false belief that the conditions for the object-level competence are normal, but only if it is exercised in abnormal conditions. So long as the exercise of the meta-competence takes place in normal conditions, it is not true that in those conditions it could easily have produced the false belief that the conditions for the object-level competence are abnormal.

The same argument, mutatis mutandis, suggests that if the second-level belief of the normal perceiver satisfies $\mathrm{C}_{i}$, it cannot fail to satisfy $\mathrm{C}_{i i}$.

We saw above that the reason Sosa adduces for the claim that the second-level belief of the kaleidoscope perceiver fails to satisfy $\mathrm{C}_{i i}$ seems to apply to the normal perceiver too. Now we can see that in both cases the reason is spurious: it is true that the envisaged dangers entail that the exercise of the meta-competence might easily have produced the false belief that the conditions for the exercise of the object-level competence are normal, but that is only because those dangers entail that the exercise of the meta-competence might easily have taken place in abnormal conditions (i.e. when the dangers materialize). But what beliefs the meta-competence would issue when exercised in abnormal conditions is irrelevant to determine whether the second-level belief it actually issues satisfies $\mathrm{C}_{i i}$, what matters for this is what beliefs it would issue when exercised in its normal conditions, and in such conditions the meta-competence simply could not issue a false belief that conditions for the exercise of the objectlevel competence are normal.

The conclusion we are lead to is that Sosa cannot obtain the epistemic disparity he wants between the kaleidoscope perceiver and the ordinary perceiver, for both have the R-knowledge that Sosa wants to grant to the ordinary perceiver but deny to the kaleidoscope perceiver. From the point of view of defending common sense 
against skepticism, this result might be welcomed, but it doesn't help handling Sosa's intuition that the kaleidoscope perceiver lacks some knowledge of the surface before him, for now it turns out that this perceiver has both A-knowledge and R-knowledge that the surface before him is red. Sosa needs to either drop the intuition he wants to explain or revise his complex condition C for aptness.

\section{Is Condition C Coherent with the Rest of Sosa's Epistemology?}

Condition $\mathrm{C}_{i i}$ raises a problem for Sosa because it doesn't let him account, in the way he wants to, for an intuition he has accepted, but $\mathrm{C}_{i i}$ appears to be problematic for Sosa's epistemology in a deeper way. Note that condition $\mathrm{C}_{i i}$ sounds a lot like a safety condition; $\mathrm{C}_{i i}$ requires that the exercise of a competence in normal conditions would not easily have issued a false belief, and safety requires of a belief that not easily would it fail by being false. Given that $\mathrm{C}_{i i}$ is part of a complex condition that a belief has to meet to be apt, it looks as if $\mathrm{C}_{i i}$ smuggles a safety condition into the complex condition for aptness. But as we saw above (section 3), one of the central thesis of Sosa's epistemology is that knowledge, both animal and reflective, requires aptness, not safety, and then, by implication, that aptness doesn't require safety. How then can $\mathrm{C}_{i i}$ be coherently introduced as a necessary condition for aptness?

Let's begin by noting some differences between condition $\mathrm{C}_{i i}$ and safety. Recall that a belief is safe if "not easily would it fail by being false, or untrue. A belief is safe provided it would have been held only if (most likely) p" (p. 25). So formulated, safety is a modal property of beliefs, whereas $\mathrm{C}_{i i}$ formulates a modal property of exercises of competences, which result in beliefs: "that exercise [of a competence] in those conditions would not then too easily have issued a false belief" (p. 33). But this difference is not important, for clearly we can formulate a safety condition for exercises of competences, which is an exact analogue of the safety condition for beliefs: the exercise of a competence is safe if not easily would it fail by resulting in a false belief. ${ }^{13}$

${ }^{13}$ Sosa himself quite often talks of safety as a property of performances in general, and of intellectual performances in particular (see, e.g., pp. 41, 139), and a natural way to understand an intellectual performance is as an exercise of an intellectual competence. However, Sosa also calls "performances" the beliefs that result from the exercise of intellectual competences; but this use of the term is metaphysically odd, since beliefs are states, whereas performances, like exercises of competences, are events. 
A more substantial difference between the two modal conditions is that $\mathrm{C}_{i i}$ is relativized to some further conditions, namely: the normal conditions for the exercise of a competence, whereas the formulation of safety doesn't contain any such relativization. However, recall that Sosa moves from "outright safety" to "basis-relative safety" as a requirement for knowledge, and the latter notion of safety is relativized to some further conditions: a belief is basis-relative safe if "it has some basis that it would not easily have had unless true, some basis that it would (likely) have had only if true" (p. 26), which is equivalent to say that the belief would not easily have been false if based on those grounds. This condition is clearly parallel to condition $\mathrm{C}_{i i}$, which can in turn be paraphrased as a safety condition: the exercise of a competence is safe relative to its normal conditions if not easily would it have issued a false belief if exercised in those conditions. The parallelism of the two conditions is striking:

[I] A belief is basis-relative safe if it would not easily have been false if based on those grounds.

[II] An exercise of a competence is safe relative to its normal conditions if it would not easily have issued a false belief if exercised in those conditions.

I suspect that $[\mathrm{I}]$ and $[\mathrm{II}]$ are mutually entailing, and therefore equivalent. It seems that (A) if a belief fulfills condition [I], then the exercise of the competence that produced it fulfills condition [II]; and (B) if an exercise of a competence fulfills [II], then the belief that it produces fulfills condition [I]. Here are arguments for both entailments.

(A) Assume a belief fulfills [I], could it be the case that it is the result of the exercise of a competence that would easily have delivered a false belief if exercised in normal conditions? If despite the fact that conditions are normal, the competence could easily have delivered a false belief, that means that the bases the belief gets in normal conditions are such that the belief could easily have been false even if based on those grounds, which contradicts the assumption that the belief fulfills [I]. So, it seems that in order to get the bases needed to be basis-relative safe, a belief must be the result of the exercise of a competence that would not easily have issued a false belief if exercised in normal conditions. If a belief fulfills [I], the exercise of the competence that produced it fulfills [II].

(B) Assume that an exercise of a competence fulfills [II], could it yield a belief that would easily have been false even if based 
on the same grounds? That would mean that the exercise of the competence in normal conditions would have given the belief some basis that it could easily have even if false. But if the exercise of the competence in normal conditions permits this, it is permitting that the belief could easily have been false relative to the normal conditions for the exercise of the competence that produced it, which contradicts the assumption that the exercise of the competence fulfills [II]. So, it seems that if a belief is the result of the exercise of a competence in normal conditions, such that in those conditions the competence would not easily produce a false belief, then the exercise of the competence gives the belief a basis such that it would not easily be false if based on those grounds. If the exercise of a competence fulfills [II], the belief it produces fulfills [I].

$\mathrm{C}_{i i}$ indeed seems to smuggle a modal condition equivalent to basis-relative safety into the conditions for aptness, which doesn't seem to be coherent with Sosa's claim that "only aptness is required for animal knowledge, not safety" (p. 34). However, a charge of incoherence against Sosa cannot be made so straightforwardly, for the kind of safety he has in mind when he makes that remark is outright safety, not basis-relative safety. In fact, at some passages he seems to be happy with the idea that basis-relative safety is a requirement for A-knowledge; he says for instance: "Outright safety is not a requirement for knowledge [...]. The more plausible requirement is dependent safety, safety dependent on a fact that also guides one's belief" (p. 102, fn. 3, his emphasis). If this is correct, then it seems that he could hold without incoherence that knowledge doesn't require outright safety but only aptness, and that aptness requires in turn a condition equivalent to basis-relative safety, namely $\mathrm{C}_{i i}$.

However, at other passages Sosa himself claims that a belief can be apt, and then animal knowledge, even if it is not basis-relative safe:

even the safety of perceptual beliefs is put in doubt by the proximity of the dream scenario. If while dreaming we hold beliefs based on sensory experiences like those of waking life, then any perceptual beliefs might too easily have been false though held on the same sensory basis, while dreaming. That is why knowledge requires not safety but aptness. Our perceptual beliefs are apt, despite how easily we might have been dreaming, so long as they are correct attributably to the exercise of a perceptual competence in its appropriate conditions. Animal knowledge is thus apt belief. (p. 98, my emphasis) 
The italicized phrase entails that, given the closeness of the danger of dreaming, no perceptual belief is basis-relative safe, for any of them has a sensory basis such that it might easily have been false despite its being held on the same sensory basis, while one is dreaming. But if basis-relative safety is not a requirement for A-knowledge, the problem reappears as to how condition $\mathrm{C}_{i i}$, which seems to be equivalent to basis-relative safety, is nevertheless a condition for Aknowledge, via its being a condition for aptness.

Sosa might reply that this apparent problem is merely apparent, that $\mathrm{C}_{i i}$ and basis-relative safety are not equivalent. But he owes us an explanation of how exactly it is possible for the two conditions to come apart; this issue is crucial for the coherence of his central theses concerning safety and aptness, which constitute the core of his virtue epistemology. ${ }^{14}$

\section{REFERENCES}

DeRose, K., 2004, "Sosa, Safety, Sensitivity and Skeptical Hypotheses", in J. Greco (ed.), Ernest Sosa and His Critics, Blackwell, Oxford, pp. 2241.

Sosa, E., 2007, A Virtue Epistemology. Apt Belief and Reflective Knowledge, Volume I, Oxford University Press, Oxford.

- 1991, Knowledge in Perspective: Selected Essays in Epistemology, Cambridge University Press, New York.

Received: March 3, 2009; revised: August 31, 2009; accepted: September 2, 2009.

${ }^{14}$ Thanks to J. Adam Carter, Leonard J. Clapp, and John Turri for comments and discussion on an earlier version of this paper, and to an anonymous referee of Crítica for his comments. 